Revista Destaques Acadêmicos, Lajeado, v. 11, n. 3, 2019. ISSN 2176-3070

DOI: http://dx.doi.org/10.22410/issn.2176-3070.v11i3a2019.2333

http://www.univates.br/revistas

\title{
QUALIDADE FISIOLÓGICA DE SEMENTES DE ARROZ TRATADAS COM ÓLEOS ESSENCIAIS E EXTRATOS VEGETAIS
}

\author{
Ingrid Naiara da Silva ${ }^{1}$, Airton José Christ ${ }^{2}$, Sumária Sousa e Silva ${ }^{3}$, \\ José Wilson Pires Carvalho ${ }^{4}$, Luiz Carlos Pascuali ${ }^{5}$
}

Resumo: Apesar da comprovada eficiência dos produtos químicos sintéticos, a agricultura moderna tem buscado formas alternativas para o tratamento de sementes e o controle de doenças, que visam uma maior preservação ambiental. Assim, o objetivo deste trabalho foi avaliar o uso de extratos e óleos essenciais de diferentes plantas no tratamento de sementes de arroz quanto a sua qualidade fisiológica. Foram usados extratos concentrados, de folhas de citronela, rizoma de gengibre, bulbo de alho e cravo-da-índia. Também foram avaliadas a combinação binária dos mesmos. Utilizouse óleos essenciais de neem, citronela, melissa, cidreira e pimenta-longa e a combinação binária dos mesmos a 5.000ppm sobre a qualidade fisiológica. Os óleos essenciais e extratos foram aplicados diretamente nas sementes, sendo $2 \mathrm{~mL}$ para $100 \mathrm{~g}$ de sementes. Os parâmetros avaliados foram: primeira contagem de germinação (Ger1), germinação (Ger), emergência em solo (EM), índice de velocidade de emergência (IVE), massa

1 Graduanda em Engenharia de Produção Agroindustrial, Faculdade e Arquitetura e Engenharias/Laboratório de Matérias-Primas e Produção de Biodiesel/Centro Tecnológico de Mato Grosso, Universidade do Estado de Mato Grosso, Barra do Bugres-MT, Brasil.

2 Professor com Graduação em Engenharia Agrícola no Curso de Produção Agroindustrial, Faculdade e Arquitetura e Engenharias/Laboratório de Matérias-Primas e Produção de Biodiesel/Centro Tecnológico de Mato Grosso, Universidade do Estado de Mato Grosso, Barra do Bugres-MT, Brasil.

3 Professora Doutora dos cursos de Engenharia de Alimentos e Produção Agroindustrial, Faculdade e Arquitetura e Engenharias/Laboratório de Matérias-Primas e Produção de Biodiesel/Centro Tecnológico de Mato Grosso, Universidade do Estado de Mato Grosso, Barra do Bugres-MT, Brasil.

4 Professor Doutor do curso de Engenharia de Alimentos, Faculdade e Arquitetura e Engenharias/Laboratório de Matérias-Primas e Produção de Biodiesel/Centro Tecnológico de Mato Grosso, Universidade do Estado de Mato Grosso, Barra do Bugres-MT, Brasil.

5 Professor Doutor do curso de Produção Agroindustrial, Faculdade e Arquitetura e Engenharias/Laboratório de Matérias-Primas e Produção de Biodiesel/Centro Tecnológico de Mato Grosso, Universidade do Estado de Mato Grosso, Barra do Bugres-MT, Brasil. 
aérea seca (MAS), massa seca radicular (MSR), comprimento plântulas aérea (CPA) e comprimento plântulas radicular (CPR). Os resultados sugerem que o tratamento com extratos não interferiu na qualidade fisiológica da semente de arroz, e que os melhores resultados foram observados para os extratos de alho e citronela e nas combinações alho-cravo-da-índia, alho-gengibre e alho-citronela. Entretanto, com exceção do óleo essencial de neen, os demais inibiram o desenvolvimento das sementes de arroz. Conclui-se que o desempenho fisiológico das sementes de arroz tratadas com extratos obteve qualidade igual ou superior a testemunha. E que os tratamentos com óleos essenciais inibiram o desenvolvimento das sementes, com exceção do óleo de neem.

Palavras-chave: Agricultura orgânica, meio ambiente, produtos naturais.

\section{INTRODUÇÃO}

O arroz é um dos cereais mais produzidos e consumidos no mundo, sendo considerado um dos principais alimentos. No Brasil apesar do arroz ser uma cultura comum em quase todos os Estados, sua produção concentra-se em algumas regiões do país. Segundo o Ministério da Agricultura, Pecuária e Abastecimento-MAPA (BRASIL, 2015) a produção do cereal concentra-se em cinco principalmente no Rio Grande do Sul, predominando o arroz irrigado, com $68,1 \%$ da produção nacional, Santa Catarina, com 8,5\%, Tocantins, com 4,8\%, Mato Grosso, 4,7\% e Maranhão com 4,6\%. Alguns fatores explicam essa afirmação, como: as características da cultura (manejo, adaptação ao tipo de solo), as exigências edafoclimáticas e as características regionais (OLIVEIRA NETO, 2015). Nesse sistema de produção, a agricultura familiar no Brasil é responsável por sete de cada dez empregos no campo e por cerca de $40 \%$ da produção agrícola, dessa forma garantindo boa parte da produção de alimentos do país, incluindo a produção de arroz (IBGE, 2006).

Entretanto, com o objetivo de aumentar a produtividade agrícola a fim de satisfazer as demandas alimentares, houve um aumento intensivo do uso de agrotóxicos sintéticos para o controle de pragas e doenças na cultura. Porém, o uso contínuo de agrotóxicos sintético tem levantando discussões, como por exemplo impactos na saúde humana e ao meio ambiente (VEIGA et al., 2006; PERES et al., 2001; MONQUERO, INÁCIO e SILVA, 2009). Além disso, a intensificação da agricultura principalmente quando se trata de monoculturas, tem demonstrado resultados prejudicais ao meio ambiente, reduzindo a diversidade biológica, causando desequilíbrios no ecossistema, principalmente no que se refere à contaminação de seres vivos e aquíferos. De modo que a contaminação tem afetado a qualidade da água, a qualidade do ar e dos alimentos, favorecendo o surgimento de novos problemas fitossanitários e o aumento de espécies nocivas às culturas, sendo o controle dessas espécies realizado com o uso de defensivos agrícolas cada vez mais potente (SOARES, 2010).

Considerando os problemas causados pelo sistema de produção convencional do arroz, que faz o uso de agrotóxicos sintéticos, diversos 
estudos (BRASIL, 2007; SILVEIRA, ANTUNES e DIAS, 2012) vêm mostrando a necessidade crescente da adoção de cultivos livres de substâncias sintéticas, como uma alternativa de redução do impacto ambiental, transformando-o em produto diferenciado no mercado, agregando valor e proporcionando maior remuneração para o produtor familiar. Dessa forma, justifica-se a utilização de produtos naturais, devido os mesmos se apresentarem como uma alternativa promissora no controle de patógenos associados às sementes, com a vantagem de redução de custos e menor impacto ambiental. Isso é possível, porque diversas plantas medicinais apresentam uma grande diversidade de substâncias com efeitos tóxicos sobre patógenos e que podem, inclusive, alterar a resistência das plantas. Dessa forma, óleos essenciais e/ou extratos de plantas medicinais podem ser utilizados em aplicação direta pelo produtor com o objetivo de inibir o desenvolvimento de fungos (GIRARDI et al., 2009; PIMENTA et al., 2019).

Neste contexto, o objetivo do presente trabalho foi avaliar a eficácia dos óleos essenciais de neem (Azadirachta indica), citronela (Cymbopogon nardus), pimenta-longa (Piper longum), capim cidreira (Cymbopogon citratus) e melissa (Melissa officinalis), e dos extratos vegetais de alho (Allium sativum L.), cravo-da-índia (Syzygium aromaticum), gengibre (Zingiber officinale) e citronela (Cymbopogon nardus), na qualidade fisiológica de sementes de arroz em diferentes concentrações.

\section{MATERIAIS E MÉTODOS}

\subsection{Obtenção e preparo dos óleos e extratos}

Os óleos essenciais foram obtidos usando folhas de capim cidreira (C. citratus), citronela (C. nardus), melissa (M. officinalis), e pimenta longa ( $P$. longum), recém colhidos do herbário da UNEMAT, Barra do Bugres, por hidrodestilação (KOKETSU e GONÇALVES, 1991), sendo o óleo de neem (A. indica) adquirido na destilaria Bauru LTDA (Lote: DBBION-ONEMPR 170315). Na preparação dos extratos vegetais, utilizou-se folhas de citronela (C. nardus) colhidas no herbário da UNEMAT, campus de Barra do Bugres, rizoma de gengibre (Z. officinale), bulbo de alho (A. sativum L.) e botões de cravo-da-índia (S. aromaticum), ambos adquiridos no mercado local. Os extratos foram mantidos sob agitação por um período de 5 dias, na proporção de $40 \mathrm{~g}$ de massa vegetal para $20 \mathrm{~mL}$ de $\mathrm{H}_{2} \mathrm{O}$ e $150 \mathrm{~mL}$ de álcool etílico. Após esse período, os mesmos foram filtrados e submetidos a evaporação em banho maria a $45^{\circ} \mathrm{C}$, resultando em um volume final de $20 \mathrm{~mL}$ do extrato concentrado. As sementes usadas nos estudos foram da cultivar caiapó, fornecidas por agricultores familiares da localidade Estrela, município de São Félix de Balsas- MA.

Para os óleos essenciais foram preparadas emulsões água-óleo na concentração $5.000 \mathrm{ppm}$, acrescido $1 \%$ (1.000 ppm) do emulsificante tween 80 , com pureza analítica. Os extratos foram usados na forma concentrada. 
Os efeitos do tratamento com óleos essenciais e com os extratos vegetais, nas sementes de arroz cultivar caiapó foram avaliados através dos testes de germinação em areia, teste de emergência em campo, índice de velocidade de emergência, comprimento das plântulas e massa seca das plântulas.

\subsection{Tratamento das sementes de arroz}

Para o tratamento das sementes de arroz foram aplicados a proporção de $2 \mathrm{~mL}$ para $100 \mathrm{~g}$ de sementes de arroz dos extratos de alho, cravo-da-índia, gengibre, citronela, alho-cravo-da-índia e das combinações binárias, alho -gengibre, alho -citronela, cravo-da-índia - gengibre, cravo-da-índia, citronela e gengibre-citronela, respectivamente. Para os óleos essenciais foi usado a mesma proporção com os óleos essenciais de neem, citronela, cidreira e melissa e as combinações binárias neem-citronela, neem-cidreira, neem-melissa, citronela-cidreira, citronela-melissa e cidreira-melissa. Também, foi realizado um controle positivo com carbendazim $(150 \mathrm{~g} / \mathrm{L})+$ tiram $(350 \mathrm{~g} / \mathrm{L})$. Além disso, a testemunha recebeu apenas água destilada.

Os testes de germinação com sementes de arroz tratadas foram realizados com quatro repetições de 200 sementes por tratamento. Após o tratamento as sementes com óleos essenciais e extratos vegetais foram semeadas em areia. As avaliações foram realizadas aos cinco dias (primeira contagem de germinação) e aos 14 dias após a semeadura, avaliando-se a porcentagem de plântulas normais para cada tratamento. A testemunha foi tratada com água destilada antes do plantio (BRASIL, 2009).

O teste de emergência foi realizado de acordo com a metodologia de Nakagawa (1991), com quatro repetições de 200 sementes por tratamento. As sementes foram semeadas em sulcos de $90 \mathrm{~cm}$ de comprimento a $3-4 \mathrm{~cm}$ de profundidade, a uma distância de $15 \mathrm{~cm}$ um do outro. A leitura foi realizada diariamente, a partir do quinto dia, até o décimo dia após a semeadura, para determinar o índice de velocidade de emergência e ao final apresentar o número de plântulas emergidas (BRASIL, 2009; PASCUALI et al., 2018).

O Índice de Velocidade de Emergência (IVE) foi determinado a partir do teste de emergência em campo, através de contagens diárias de plântulas normais, até a estagnação da emergência. Com base no número de plantas emergidas, foi calculado o IVE, empregando-se a Equação IVE= (G1/N1) + $(\mathrm{G} 2 / \mathrm{N} 2)+\ldots+(\mathrm{Gn} / \mathrm{Nn})$, (BRASIL, 2019). Em que: $\mathrm{G}=$ número de plântulas normais computadas nas contagens; $\mathrm{N}=$ número de dias da semeadura à $1^{\mathrm{a}}$, $2^{\mathrm{a}} \ldots$ enésima avaliação.

O comprimento de plântulas foi realizado conforme a técnica do rolo de papel, com quatro repetições de 20 sementes para cada tratamento. $O$ papel de germinação foi pré-umedecido com água destilada e as sementes foram distribuídas sobre duas folhas e sobrepostas com mais duas folhas e enroladas em forma de rolo. Os rolos foram mantidos, no germinador, na posição vertical, 
a $25^{\circ} \mathrm{C}$. As avaliações foram realizadas no quinto dia através da medição do comprimento radicular e do hipocótilo das plântulas normais, sendo os resultados expressos em centímetros (BRASIL, 2009; PASCUALI et al., 2018).

Massa seca das plântulas: com o término do teste de germinação, as plântulas foram separadas em raiz e parte aérea. Em seguida, acondicionadas em sacos de papel Kraft postas para secar em estufa com circulação de ar forçado a $70{ }^{\circ} \mathrm{C}$, por $24 \mathrm{~h}$. Após esse período, as amostras foram pesadas em balança semi-analítica e o resultado expresso em miligrama.

\subsection{Análise estatística}

O delineamento experimental foi completamente casualizado, com quatro repetições por tratamento. E as comparações de médias foram realizadas com o uso do software WinSat 1.0 a $5 \%$ de probabilidade, pelo teste de Duncan (MACHADO; CONCEIÇÃO, 2005).

\section{RESULTADOS e DISCUSSÃO}

\subsection{Efeitos dos tratamentos com extratos vegetais concentrados na qualidade fisiológica das sementes de arroz}

Os resultados da primeira contagem de germinação (Ger1), germinação (Ger); Emergência em solo (EM); índice de velocidade de emergência (IVE); massa seca aérea (MSA); massa seca radicular (MSR); comprimento plântulas aérea (CPA), comprimento plântulas radicular (CPR), são apresentados na Tabela 1.

Os valores obtidos no teste de primeira contagem de germinação (TABELA 1), indicam que os extratos vegetais de alho, cravo-da-índia, gengibre, citronela, e suas combinações, não interferiram no vigor das sementes, por apresentar valores em porcentagem similar à testemunha e aos resultados obtidos com o tratamento com carbendazim $(150 \mathrm{~g} / \mathrm{L})+$ tiram $(350 \mathrm{~g} / \mathrm{L})$. Além disso, para a germinação (Ger) a combinação dos extratos de alho-citronela apresentou o melhor resultado com $92 \%$, valor esse superior ao observado para testemunha e o controle positivo com carbendazim (150 g/L)+ tiram $(350 \mathrm{~g} / \mathrm{L})$. Esses resultados sugerem que essa combinação de extratos de alho-citronela melhorou a germinação das sementes de arroz (TABELA 1). Entretanto, o tratamento com a combinação de extratos de cravo-da-índia-citronela levou a um retardamento na germinação das sementes de arroz. Os demais extratos e combinações binárias não apresentaram diferenças significativas em relação a testemunha (TABELA 1). 
Tabela 1: Qualidade fisiológica das sementes de arroz tratadas com extratos vegetais concentrados

\begin{tabular}{l|l|l|l|l|l|l|l|l}
\hline \multicolumn{7}{c}{ Tratamentos com extratos separadamente } \\
\hline Tratamentos & Ger1 & Ger & EM & IVE & MSA & MSR & CPA & CPR \\
\hline Alho & $28^{\mathrm{abc}}$ & $89^{\mathrm{ab}}$ & $85^{\mathrm{a}}$ & $12,8^{\mathrm{a}}$ & $5,1^{\mathrm{ab}}$ & $5,5^{\mathrm{a}}$ & $1,7^{\mathrm{ab}}$ & $6,0^{\mathrm{ab}}$ \\
\hline Cravo-da-Índia & $20^{\mathrm{abc}}$ & $82^{\mathrm{ed}}$ & $87^{\mathrm{a}}$ & $12,9^{\mathrm{a}}$ & $4,9^{\mathrm{ab}}$ & $5,2^{\mathrm{a}}$ & $1,6^{\mathrm{ab}}$ & $5,3^{\mathrm{ab}}$ \\
\hline Gengibre & $38^{\mathrm{a}}$ & $89^{\mathrm{ab}}$ & $90^{\mathrm{a}}$ & $13,6^{\mathrm{a}}$ & $5,0^{\mathrm{ab}}$ & $5,4^{\mathrm{a}}$ & $1,8^{\mathrm{ab}}$ & $6,1^{\mathrm{ab}}$ \\
\hline Citronela & $27^{\mathrm{abc}}$ & $88^{\mathrm{ab}}$ & $54^{\mathrm{c}}$ & $7,4^{\mathrm{c}}$ & $5,4^{\mathrm{a}}$ & $4,9^{\mathrm{a}}$ & $1,9^{\mathrm{ab}}$ & $6,2^{\mathrm{ab}}$ \\
\hline Alho-Cravo-da-índia & $14^{\mathrm{bc}}$ & $85^{\mathrm{bc}}$ & $88^{\mathrm{a}}$ & $13,6^{\mathrm{a}}$ & $5,1^{\mathrm{ab}}$ & $6,1^{\mathrm{a}}$ & $1,9^{\mathrm{ab}}$ & $5,5^{\mathrm{ab}}$ \\
\hline Alho - Gengibre & $20^{\mathrm{abc}}$ & $87^{\mathrm{b}}$ & $87^{\mathrm{a}}$ & $12,8^{\mathrm{a}}$ & $4,7^{\mathrm{ab}}$ & $6,8^{\mathrm{a}}$ & $2,2^{\mathrm{a}}$ & $5,9^{\mathrm{ab}}$ \\
\hline Alho - Citronela & $10^{\mathrm{bc}}$ & $92^{\mathrm{a}}$ & $65^{\mathrm{bc}}$ & $8,6^{\mathrm{bc}}$ & $4,7^{\mathrm{ab}}$ & $5,8^{\mathrm{a}}$ & $2,1^{\mathrm{a}}$ & $5,8^{\mathrm{ab}}$ \\
\hline Cravo-da-Índia-gengibre & $10^{\mathrm{bc}}$ & $82^{\mathrm{cd}}$ & $87^{\mathrm{a}}$ & $13,0^{\mathrm{a}}$ & $4,2^{\mathrm{b}}$ & $5,5^{\mathrm{a}}$ & $2,0^{\mathrm{ab}}$ & $5,0^{\mathrm{b}}$ \\
\hline Cravo-da-Índia-Citronela & $6,0^{\mathrm{c}}$ & $80^{\mathrm{d}}$ & $85,5^{\mathrm{a}}$ & $12,6^{\mathrm{a}}$ & $4,4^{\mathrm{b}}$ & $5,3^{\mathrm{a}}$ & $1,8^{\mathrm{ab}}$ & $4,9^{\mathrm{b}}$ \\
\hline Gengibre-Citronela & $26^{\mathrm{abc}}$ & $89^{\mathrm{ab}}$ & $69^{\mathrm{b}}$ & $9,6^{\mathrm{b}}$ & $5,0^{\mathrm{ab}}$ & $5,7^{\mathrm{a}}$ & $2,1^{\mathrm{a}}$ & $6,5^{\mathrm{a}}$ \\
\hline Testemunha & $29^{\mathrm{ab}}$ & $86^{\mathrm{bc}}$ & $60^{\mathrm{bc}}$ & $7,9^{\mathrm{bc}}$ & $4,9^{\mathrm{ab}}$ & $5,7^{\mathrm{a}}$ & $1,9^{\mathrm{ab}}$ & $5,3^{\mathrm{ab}}$ \\
\hline $\begin{array}{l}\text { Carbendazim (150g/L)+ } \\
\text { tiram (350g/L) }\end{array}$ & $11^{\mathrm{bc}}$ & $85^{\mathrm{bc}}$ & $92^{\mathrm{a}}$ & $14,2^{\mathrm{a}}$ & $5,0^{\mathrm{ab}}$ & $4,9^{\mathrm{a}}$ & $1,4^{\mathrm{b}}$ & $5,0^{\mathrm{b}}$ \\
\hline
\end{tabular}

Ger1=Primeira contagem de germinação (\%), Ger= Segunda Contagem de Germinação (\%); EM= Emergência em solo (\%); IVE= Índice de Velocidade de Emergência; MSA= Massa seca - aérea; MSR Massa seca - radicular; $\mathrm{CPA}=$ Comprimento Plântulas - aérea $(\mathrm{cm}) ; \mathrm{CPR}=\mathrm{Comprimento}$ Plântulas - radicular $(\mathrm{cm})$.

* médias seguidas pelas mesmas letras na coluna não diferem entre si pelo teste de Duncan a 5\% de probabilidade.

Fonte: Elaborado pelos autores

Nesse sentido, estudos mostram que extrato de sorgo (Sorghum bicolor) concentrado levou a uma diminuição na germinação de sementes de milho (Zea mays), de 97\% (testemunha) para 91\% (tratada com extrato), enquanto que, a porcentagem de germinação das ementes de corda-de-viola (Ipomoea sp.) não foi afetada pelo tratamento com o mesmo extrato (GOMES et al., 2018). Estudos com extrato concentrado (100\%) das folhas e fruto do maracujá azedo (Passiflora edulis Sims) mostram que o mesmo levou a uma redução da percentagem de germinação de sementes de alface (Lactuca sativa L.) de 97,5 \% (testemunha) para 84,50 e $80,80 \%$ na presença de extrato das folhas e fruto do maracujá azedo, respectivamente (GOMES et al., 2018).

As porcentagens de emergência em solo sugerem que o efeito dos extratos vegetais de alho, cravo-da-índia, gengibre, e as combinações alhocravo-da-índia, alho-gengibre, cravo-da-índia-gengibre e cravo-da-índiacitronela, favoreceram o desenvolvimento das sementes, com desempenho superior a testemunha e não diferindo estatisticamente do resultado observado para as sementes tratadas com o fungicida comercial. Os demais tratamentos apresentaram resultados similares entre si, com valores de emergência em solo para as sementes tratadas com o extrato de citronela e a combinação gengibre- 
citronela ligeiramente menores, entretanto, não diferem da testemunha (TABELA 1).

O índice de velocidade de emergência mostra a mesma tendência observada para a EM, onde os melhores resultados foram obtidos com tratamento com extrato de gengibre, alho, cravo-da-índia e as combinações, alho-cravoda-índia, cravo-da-índia-gengibre e cravo-da-índia-citronela, similar ao obtido com o fungicida carbendazim $150 \mathrm{~g} / \mathrm{L}+$ tiram $350 \mathrm{~g} / \mathrm{L}$. Estudos com sementes de tomate usando extratos de babosa (Aloe vera) e boldo brasileiro (Plectranthus barbatus), com concentração variando de $2-16 \%$, mostraram que não houve interferência na emergência em solo (LORENSI et al., 2017). No entanto, uma diminuição significativa na emergência em solo foi observada para sementes de alface (Lactuca sativa L.) com o aumento da concentração de extratos de juazeiro (Ziziphus joazeiro Mart.) e catingueira (Caesalpinia pyramidalis Tul.) de 10 a 100\% (OLIVEIRA et al., 2015).

Os valores de Massa Seca Aérea (MSA) das plântulas de arroz sugerem que os extratos, separadamente, assim como as combinações binárias não afetaram a transferência de reservas das sementes para as plântulas, com exceção dos tratamentos com as combinações dos extratos de cravo-da-índiagengibre e cravo-da-índia-citronela, que levaram a uma redução na MSA das plântulas, em relação à testemunha e ao controle positivo com fungicida comercial (TABELA 1). Contanto, as porcentagens de Massa Seca Radicular (MSR), praticamente, não diferiram entre si, com exceção das que foram tratadas com as combinações de extratos de cravo-da-índia-gengibre e cravoda-índia-citronela, que apresentaram MSR menor (TABELA 1).

Quanto ao comprimento de plântulas aérea (CPA) de arroz apresentado na Tabela 1, pode-se observar que a combinação de extratos de alho-gengibre, alho-citronela e gengibre-citronela melhores do que com o tratamento com fungicida comercial, no entanto, esses resultados diferem estatisticamente entre si e da testemunha. Além disso, resultados similares são observados para comprimento plântulas radicular ( $\mathrm{CPR}$ ), em que os valores de CPR obtidos para os tratamentos com extratos separadamente e combinações binárias não diferem estatisticamente da testemunha (TABELA 1).

Estudos realizados por Oliveira (2015) com extratos aquosos de folhas frescas de juazeiro (Ziziphus joazeiro Mart.) e catingueira (Caesalpinia pyramidalis Tul.) também não observaram mudanças significativas para a porcentagem de MSA, MSR e CPA, para sementes de alface (Lactuca sativa L.). Entretanto, extratos aquosos de folhas, cascas e vagens maduras de jucá (Caesalpinea ferrea) mostraram-se fitotóxicos sobre o desenvolvimento inicial de plântulas de alface, e quando os mesmos foram obtidos com aquecimento a $100^{\circ} \mathrm{C}$ (OLIVEIRA et al., 2012). Além disso, os extratos das folhas e vagens provocaram uma diminuição da germinação das sementes de alface.

A conservação da qualidade fisiológica das sementes de arroz observada na maioria dos tratamentos realizados com extratos de alho, cravo-da-índia, 
gengibre e citronela e as respectivas combinações binárias é um resultado relevante, considerando que os referidos extratos geralmente contêm moléculas bioativas denominadas de aleloquímicas, que são metabólitos secundários das plantas, que podem prejudicar o desenvolvimento da semente tratada (MAIRESSE et al., 2007).

Efeitos de metabólitos secundários (biomoléculas aleloquímicas) foram observados em sementes de alface (Lectuca sativa), soja (Glycine max L. Merr.) (RICKLI et al., 2011) e feijão (P. vulgares) (SILVA, CROTTI e CUNHA, 2007). É conhecido que a preparação de extrato com uso de álcoois contribui para a extração de biomoléculas aleloquímicas (ARAÚJO et al., 2014). E mesmo não tendo sido quantificado esse tipo de moléculas no presente trabalho, os resultados sugerem esses metabólitos estavam em concentrações baixas ou insuficientes, na maioria dos extratos usados no presente estudo, para influenciarem no desempenho das sementes de arroz (TABELA 1).

\subsection{Efeitos dos tratamentos com óleos essenciais na qualidade fisiológica de sementes de arroz}

Os resultados de primeira contagem de germinação (Ger1), germinação (Ger); Emergência em solo (EM); Índice de Velocidade de Emergência (IVE); Massa Seca Aérea (MSA); Massa Seca-Radicular (MSR); Comprimento Plântulas Aérea (CPA), Comprimento Plântulas Radicular (CPR) para semente de arroz tratadas com óleos essenciais de neem, citronela, cidreira e melissa separadamente e com combinações binárias, são mostrados na Tabela 2.

Os dados de Ger1 para as sementes de arroz tratadas com óleos essenciais de neem, citronela, cidreira, melissa, e suas combinações binárias levaram a uma diminuição na porcentagem, enquanto, as sementes tratadas com o fungicida carbendazim $(150 \mathrm{~g} / \mathrm{L})+$ tiram $(350 \mathrm{~g} / \mathrm{L})$ apresentaram porcentagem de germinação similar a testemunha tratada com água destilada (TABELA 2). Para Ger, as sementes tratadas com óleo de neem apresentaram o melhor resultado, com porcentagem de germinação de $80 \%$, enquanto, as tratadas com óleo de citronela, cidreira e melissa incluindo as combinações que continham óleo essencial de neem praticamente não germinaram (TABELA 2).

Tabela 2: Qualidade fisiológica de sementes de arroz tratadas com os óleos essenciais

\begin{tabular}{c|c|c|c|c|c|c|c|c}
\hline Tratamentos & Ger1 & Ger & EM & IVE & MSA & MSR & CPA & CPR \\
\hline Neem & $0^{\mathrm{c}}$ & $80^{\mathrm{b}}$ & $67^{\mathrm{b}}$ & $7,3^{\mathrm{b}}$ & $4,2^{\mathrm{b}}$ & $4,8^{\mathrm{a}}$ & $1,3^{\mathrm{ab}}$ & $3,6^{\mathrm{b}}$ \\
\hline Citronela & $0^{\mathrm{c}}$ & $0^{\mathrm{c}}$ & $0^{\mathrm{d}}$ & $0^{\mathrm{d}}$ & $0^{\mathrm{c}}$ & $0,1^{\mathrm{b}}$ & $0,9^{\mathrm{bc}}$ & $2,3^{\mathrm{bcd}}$ \\
\hline Cidreira & $0^{\mathrm{c}}$ & $0^{\mathrm{c}}$ & $0^{\mathrm{d}}$ & $0^{\mathrm{d}}$ & $0^{\mathrm{c}}$ & $0^{\mathrm{b}}$ & $0^{\mathrm{c}}$ & $0,7^{\mathrm{cd}}$ \\
\hline Melissa & $0^{\mathrm{c}}$ & $1^{\mathrm{c}}$ & $0^{\mathrm{d}}$ & $0^{\mathrm{d}}$ & $0,7^{\mathrm{c}}$ & $0,5^{\mathrm{b}}$ & $0^{\mathrm{c}}$ & $0^{\mathrm{d}}$ \\
\hline Neem-Citronela & $0^{\mathrm{c}}$ & $1^{\mathrm{c}}$ & $0^{\mathrm{d}}$ & $0^{\mathrm{d}}$ & $0,8^{\mathrm{c}}$ & $1,2^{\mathrm{b}}$ & $0^{\mathrm{c}}$ & $0^{\mathrm{d}}$ \\
\hline Neem-Cidreira & $0^{\mathrm{c}}$ & $0^{\mathrm{c}}$ & $0^{\mathrm{d}}$ & $0^{\mathrm{d}}$ & $0,1^{\mathrm{c}}$ & $0,1^{\mathrm{b}}$ & $0^{\mathrm{c}}$ & $0^{\mathrm{d}}$ \\
\hline
\end{tabular}




\begin{tabular}{c|c|c|c|c|c|c|c|c}
\hline Tratamentos & Ger1 & Ger & EM & IVE & MSA & MSR & CPA & CPR \\
\hline Neem-Melissa & $0^{\mathrm{c}}$ & $1^{\mathrm{c}}$ & $0^{\mathrm{d}}$ & $0^{\mathrm{d}}$ & $0,4^{\mathrm{c}}$ & $0,3^{\mathrm{b}}$ & $0^{\mathrm{c}}$ & $0^{\mathrm{d}}$ \\
\hline Citronela-Cidreira & $0^{\mathrm{c}}$ & $2^{\mathrm{c}}$ & $0,8^{\mathrm{d}}$ & $0^{\mathrm{d}}$ & $0,8^{\mathrm{c}}$ & $0,3^{\mathrm{b}}$ & $0^{\mathrm{c}}$ & $3,1^{\mathrm{bc}}$ \\
\hline Citronela-Melissa & $0^{\mathrm{c}}$ & $0^{\mathrm{c}}$ & $0^{\mathrm{d}}$ & $0^{\mathrm{d}}$ & $0^{\mathrm{c}}$ & $0^{\mathrm{b}}$ & $1,2^{\mathrm{ab}}$ & $4,2^{\mathrm{ab}}$ \\
\hline Cidreira-Melissa & $0^{\mathrm{c}}$ & $0^{\mathrm{c}}$ & $13^{\mathrm{c}}$ & $1,7^{\mathrm{c}}$ & $0^{\mathrm{c}}$ & $0^{\mathrm{b}}$ & $1,2^{\mathrm{ab}}$ & $3,6^{\mathrm{b}}$ \\
\hline Testemunha & $30^{\mathrm{a}}$ & $92^{\mathrm{a}}$ & $91^{\mathrm{a}}$ & $14,1^{\mathrm{a}}$ & $5,3^{\mathrm{a}}$ & $3,8^{\mathrm{a}}$ & $1,9^{\mathrm{a}}$ & $6,5^{\mathrm{a}}$ \\
\hline $\begin{array}{c}\text { Carbendazim } \\
(150 \mathrm{~g} / \mathrm{L})+\text { tiram } \\
(350 \mathrm{~g} / \mathrm{L}) \AA\end{array}$ & $25^{\mathrm{b}}$ & $91^{\mathrm{a}}$ & $92^{\mathrm{a}}$ & $14,2^{\mathrm{a}}$ & $5,2^{\mathrm{a}}$ & $3,9^{\mathrm{a}}$ & $1,4^{\mathrm{ab}}$ & $4,9^{\mathrm{ab}}$ \\
\hline
\end{tabular}

Ger1=Primeira contagem de germinação (\%), Ger= Germinação (\%);EM= Emergência em solo (\%); IVE= Índice de Velocidade de Emergência; MSA= Massa seca aérea; MSR Massa seca radicular; $\mathrm{CPA}=$ Comprimento Plântulas - aérea $(\mathrm{cm}) ; \mathrm{CPR}=$ Comprimento plântulas radicular $(\mathrm{cm})$.

Fonte: Elaborado pelos autores

Gomes et al. (2008) observaram que o emprego do óleo essencial na concentração 15.000 ppm de neem não interferiu na germinação de sementes de soja, quando comparadas a testemunha. $\mathrm{O}$ mesmo não foi verificado em nosso estudo, onde o tratamento com o óleo essencial de neem apresentou o melhor índice de germinação de sementes de arroz. No entanto, estudos usando óleos essenciais no tratamento de sementes de soja, milho, feijão e feijão-fava tem mostrado efeitos positivos na qualidade fisiológica (GOMES et al., 2016; DOMENE et al., 2016; HILLEN et al., 2012; BRITO et al., 2012). Como nos estudos com 500, 1.000, 1.500 e 2.000 ppm de óleos de copaíba (Copaifera langsdorffii Desf.) e cravo-da-índia (Caryophyllus aromaticus L.) mostram um aumento na porcentagem de germinação de sementes de feijão-fava (Phaseolus lunatus L.) (GOMES et al., 2016).

Por outro lado, estudos com óleo essencial de citronela (Citronela nardus) e eucalipto (na faixa de concentração de 50.000 a 150.000 ppm, mostram uma redução significativa na germinação (cintronela de 28 para $2 \%$ e eucalipto de 58 para $7 \%$ ) de sementes de milho (Zea mays) (BRITO et al., 2012). Estudos com 15.000 ppm de óleo de neem no tratamento de sementes de soja também mostram redução na germinação (GOMES et al., 2016) e com 500, 1.000, 1.500 e 2.000 ppm de óleo essencial de manjericão (Ocimum basilicum L.), que reduziu a porcentagem de germinação de feijão-fava (Phaseolus lunatus L., (GOMES et al., 2016).

A emergência em solo (EM) e o índice de velocidade de emergência (IVE), são similares para os tratamentos com óleos essenciais de citronela, cidreira, melissa e as combinações neem-citronela, neem-cidreira, neemmelissa, citronela-cidreira e citronela-melissa, com valores praticamente iguais a zero, ou seja, a presença do óleo essencial impediu o desenvolvimento das sementes de arroz (TABELA 2). No entanto, o tratamento com óleo essencial de neem separadamente e a combinação cidreira-melissa apresentaram os melhores resultados de EM de 67 e 13\% e IVE, 7,3 e 1,7\%, respectivamente. As porcentagens de MSA e MSR (TABELA 2), mostram que os óleos essenciais de 
neem, citronela, cidreira, melissa, e suas combinações apresentaram resultados similares aos observado para EM e IVE, onde a presença dos óleos essenciais praticamente inibiram o crescimento das plântulas de arroz. A mesma tendência pode ser observada para o CPA e CPR, com exceção para o tratamento com o óleo essencial de neem, o qual apresentou MSR e CPA que não diferiu da testemunha e do tratamento com fungicida (TABELA 2).

Estudos de GOMES et al. (2016) avaliaram a eficiência dos óleos essenciais de copaíba, cravo-da-índia e manjericão na fixa de concentração de 1.000 a 2.000 ppm, na redução da incidência de fungos associados às sementes de feijão-fava (Phaseolus lunatus L.), e a interferência na qualidade fisiológica. Nas análises de comprimento da parte aérea, raiz primária e plântula, foi constatada diferença significativa na presença dos óleos essenciais em todas as concentrações. Quando utilizados os tratamentos com óleo de cravo-daíndia na concentração de 2.000 ppm e de manjericão na concentração de 1.000 ppm observou-se uma redução no comprimento da parte aérea e plântula, influenciando negativamente no vigor das plântulas de feijão-fava.

Análises sobre os efeitos em sementes de milho da variedade AL Bandeirante de óleos essenciais provenientes de folhas de C. citriodora e $E$. camaldulensis, a $3.400 \mathrm{ppm}$ dissolvido em acetona, e mostraram comprimento de plântulas. Demonstrando que na presença do óleo de C. citriodora não houve mudanças significativas no desenvolvimento da plântula, enquanto que o de $E$. camaldulensis, causou uma diminuição do comprimento de plântula (DOMENE et al., 2016). Estudos com sementes de alface usando óleos essenciais de canela (Cinnamomum zeylanicum), alecrim-pimenta (Lippiasi doides), capimcitronela (Cymbopogon citratus), alfavaca-cravo (Ocimum gratissimum) e jaborandi (Policarpus microphyllus) variando a concentração de 10 a 10.000 ppm mostraram uma redução no crescimento da plântula de alface com o aumento da concentração, exceto para o óleo de jaborandi, que estimulou o crescimento das plântulas (ALVES et al., 2004).

\section{CONCLUSÃO}

Os resultados de desempenho fisiológico das sementes de arroz tratadas com extratos mostram que as sementes mantiveram a qualidade com resultados iguais ou superiores a testemunha. Dessa forma, o presente estudo mostra que a aplicação de extratos no tratamento de sementes de arroz pode ser uma alternativa segura e eficiente quanto à qualidade fisiológica das sementes. Entretanto, os tratamentos com óleos essenciais praticamente inibiram o desenvolvimento das sementes, com exceção do óleo de neem, que apresentou de MSR e CPA que não diferem da testemunha. 


\section{AGRADECIMENTOS}

À Fundação de Amparo à Pesquisa do Estado de Mato Grosso (FAPEMAT), pelo suporte financeiro (Edital $n^{\circ}$ 042/2016 Universal, processo $\mathrm{n}^{\circ}$ 0214457/2017; Edital DCR n ${ }^{\circ} 003 / 2016$, processo $\left.n^{\circ} 0575980 / 2017\right)$, ao CNPq processo $n^{\circ} 313859 / 2017-5$ e ao Centro Tecnológico de Mato Grosso (CTMAT), pertencente à Universidade do Estado de Mato Grosso (UNEMAT), campus de Barra do Bugres, MT.

\section{REFERÊNCIAS}

ALVES, Maria da Conceição Sampaio et al. Alelopatia de extratos voláteis na germinação de sementes e no comprimento da raiz de alface. Pesquisa agropecuária brasileira, v. 39, n. 11, p. 1083-1086, 2004.

ARAÚJO, Emmanuelle Rodrigues et al. Extratos de Piper marginatume azadirachta indica no controle de Colletotrichum scovillei em pimentão. Pesquisa Agropecuária Brasileira, v. 49, n. 2, p. 88-94, 2014.

BRASIL. Ministério da Agricultura, Pecuária e Abastecimento. Cadeia produtiva de produtos orgânicos / Ministério da Agricultura, Pecuária e Abastecimento, Secretaria de Política Agrícola, Instituto Interamericano de Cooperação para a Agricultura; coordenadores Antônio Márcio Buainain e Mário Otávio Batalha. - Brasília: IICA: MAPA/SPA, 108 p: 17,5 x 24 cm - (Agronegócios; v.5), 2007.

BRASIL. Ministério da Agricultura, Pecuária e Abastecimento. Projeções do Agronegócio, Brasil 2014/15 a 2024/25, Projeções de Longo Prazo. 6. Ed - Brasília: Mapa, p. 22-26, 2015.

BRASIL. Ministério da Agricultura, Pecuária e Abastecimento. Regras para análise de sementes. Secretaria de Defesa Agropecuária. - Brasília: Mapa/ACS, p. 399. 2009.

BRITO, Deyvid Rocha et al. Efeito dos óleos de citronela, eucalipto e composto citronela sobre microflora e desenvolvimento de plantas de milho. Journal of Biotechnology and Biodiversity, v. 3, n.4, p.184-192, 2012.

DOMENE, Maria Paula et al. Efeito do tratamento com óleos essenciais sobre a qualidade fisiológica e sanitária das sementes de milho (Zea mays). Arquivos do Instituto Biológico, v.83, n.1, p. e0072014- e0072014, 2016.

DOMENE, Maria Paula et al. Efeito do tratamento com óleos essenciais sobre a qualidade fisiológica e sanitária das sementes de milho (Zea mays). Arquivos do Instituto Biológico, v. 83, n.1-6, p e0072014- e0072014, 2016.

GIRARDI, Leonita B et al. Extratos vegetais na qualidade fisiológica e sanitária de sementes de zínia (Zinni aelegans). Revista Brasileira de Agroecologia, v. 4, n. 2, p. 897-900, 2009. 
GOMES, R. S. S. et al. Eficiência de óleos essenciais na qualidade sanitária e fisiológica em sementes de feijão-fava (Phaseolus lunatus L.). Revista Brasileira de Plantas

Medicinais, v. 18, n. 1, supl. 1, p. 279-287, 2016.

GOMES, Talita Camargos et al. Ação de extratos de sorgo na germinação de sementes de milho, alface e corda-de-viola (Ipomoea sp.). Embrapa Milho e Sorgo-Nota Técnica/ Nota Científica (ALICE), 2018.

HILLEN, T. et al. Atividade antimicrobiana de óleos essenciais no controle de alguns fitopatógenos fúngicos in vitro e no tratamento de sementes. Revista Brasileira de Plantas Medicinais, v. 14, n. 3, p. 439-445, 2012.

IBGE-Instituto Brasileiro de Geografia e Estatística. Censo Agropecuário. Rio de Janeiro, 146 p, 2006.

KOKETSU, Midori; GONÇALVES, Sueli L. Óleos essenciais e sua extração por arraste a vapor. Rio de Janeiro, EMBRAPA - CTAA, 1991.

LORENSI, Christina A. et al. Alelopatia de extratos vegetais na germinação e crescimento inicial do tomateiro. Enciclopédia Biosfera, v.14, n. 25, p 185-195, 2017.

MACHADO, A. de A.; CONCEIÇÃO, Adriano Rochedo. WinStat: sistema de análise estatística para Windows. Versão Beta. Pelotas: Universidade Federal de Pelotas, 2005.

MAIRESSE, Luiz Alberto Silveira et al. Bioatividade de extratos vegetais sobre alface (Lactuca sativa L.). Revista da FZVA, v. 14, n. 2, 2007.

MONQUERO, Patrícia A.; INÁCIO Estela M.; SILVA Andréia C. Levantamento de agrotóxicos e utilização de equipamento de proteção individual entre os agricultores da região de Araras. Arquivos do Instituto Biológico, v. 76, n. 1, p.135-139, 2009.

NAKAGAWA, João. Testes de vigor baseados na avaliação de plântulas. In: KRZYZANOWSKI, Francisco Carlos; VIEIRA, Maria das Graças Guimarães Carvalho.; FRANÇA-NETO, José de Barros (Ed.). Vigor de sementes: conceitos e testes. Londrina: ABRATES, p.2:1- 2:21, 9991.

OLIVEIRA, Andreya Kaliana et al. Atividade alelopática de extratos de diferentes orgãos de Caesalpinia ferrea na germinação de alface. Ciência Rural, v. 42, n. 8, p. 13971403, 2012.

OLIVEIRA NETO, Aroldo A. A cultura do arroz. Brasília: Companhia Nacional de Abastecimento, 2015.

OLIVEIRA, A. S. L. et al. Extratos de juazeiro e catingueira são alelopáticos às plântulas de alface. Enciclopédia Biosfera, v. 11, n. 21, p. 230-242, 2015. 
PASCUALI, Luiz Carlos et al. Atividade de bioextratos no desenvolvimento de Phomopsis phaseoli var. sojae, Fusarium sp e no tratamento de sementes de soja. Revista em Agronegócio e Meio Ambiente, v.11, n.2, p. 457-478, 2018.

PERES, Frederico et al. Comunicação relacionada ao uso de agrotóxicos em região agrícola do Estado do Rio de Janeiro. Cadernos de Saúde Pública, v. 35, n. 6, p. 564$702,2001$.

PIMENTA Eduardo et al. Avaliação da atividade antifúngica do óleo essencial de Pogostemon cablin (Blanco) Benth. (Lamiaceae) contra cepas de Candida glabrata. Scientia Plena, v.15, n. 6, p. 1-5, 2019.

RICKLI, Helena Cristina et al. Efeito alelopático de extrato aquoso de folhas de Azadirachta indica A. Juss. em alface, soja, milho, feijão e picão-preto. Semina: ciências agrárias, v. 32, n. 2, p. 473-483, 2011.

SILVA, José de Paula da; CROTTI, Antonio Eduardo Miller; CUNHA, Wilson Roberto. Antifeedant and allelopathic activities of the hydroalcoholic extract obtained from neem (Azadirachta indica) leaves. Revista Brasileira de Farmacognosia, v.17, n.4, p.529$532,2007$.

SILVEIRA, Vanessa M.; ANTUNES, Graziela M.; DIAS, Marcelo Fernandes P. Inovação em sistemas de produção de arroz orgânico no Rio Grande do Sul. Brazilian Journal Management, v. 5, n. especial, p. 715-728, 2012.

SOARES, Wagner L. Uso dos agrotóxicos e seus impactos à saúde e ao meio ambiente: uma avaliação integrada entre a economia, a saúde pública, a ecologia e a agricultura. 2010. 150f. Tese de Doutorado (Saúde Pública e Meio Ambiente) Fundação Oswaldo Cruz, Escola Nacional de Saúde Pública Sergio Arouca, Rio de Janeiro, 2010.

VEIGA, Marcelo M. et al. Análise da contaminação dos sistemas hídricos por agrotóxicos numa pequena comunidade rural do Sudeste do Brasil. Cadernos de Saúde Pública, v. 22, n. 11, p. 2391-2399, 2006. 